\title{
Surface Modification of PES Hollow Fiber Membranes using Iron Oxide Particles for Water Treatment: Does Particle Size Really Matter?
}

\author{
Nadiene Salleha Mohd Nawi $i^{a, b}$, Woei Jye Lau ${ }^{a, b, *}$, Norhaniza Yusof ${ }^{a, b}$, Noresah \\ Said $^{a, b}$, Ahmad Fauzi Ismail ${ }^{a, b}$ \\ ${ }^{a}$ Advanced Membrane Technology Research Centre (AMTEC), Universiti Teknologi

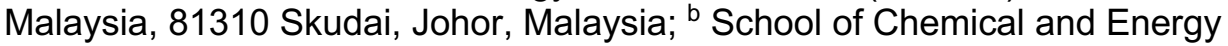 \\ Engineering, Universiti Teknologi Malaysia, 81310 Skudai, Johor, Malaysia
}

*For correspondence: Iwoeijye@utm.my

Received: 11 August 2021 Accepted: 11 October 2021

(C) Copyright Nawi. This article is distributed under the terms of the Creative Commons Attribution License, which permits unrestricted use and redistribution provided that the original author and source are credited.
Abstract Factors such as particle type and its loading have been previously studied in tailoring the efficiency of particles-modified polymeric membranes for water treatment. However, the role of particle sizes in membrane modification is often overlooked. Thus, in this work, two commercial iron oxide $\left(\mathrm{Fe}_{3} \mathrm{O}_{4}\right)$ particles (i.e., $50-100 \mathrm{~nm}$ and $<5 \mu \mathrm{m}$ ) were separately incorporated into $20 \mathrm{wt} \%$ polyethersulfone (PES) dope solution via blending method followed by dry/wet spinning process to produce hollow fiber membranes. Subsequently, a series of analytical instruments and filtration assessment to study the impacts of $\mathrm{Fe}_{3} \mathrm{O}_{4}$ particle size on membrane properties. Results revealed that the addition of smaller $\mathrm{Fe}_{3} \mathrm{O}_{4}$ particles into PES solution produced membrane with better hydrophilicity (contact angle: $75.77^{\circ}$ ) and consequently higher pure water flux (PWF) (110.42 $\mathrm{L} / \mathrm{m}^{2}$.h.bar) compared to the pristine PES membrane $\left(82.60 \mathrm{~L} / \mathrm{m}^{2}\right.$.h.bar) and the membrane with larger $\mathrm{Fe}_{3} \mathrm{O}_{4}$ particles $\left(91.54 \mathrm{~L} / \mathrm{m}^{2}\right.$.h.bar). This is due to the better dispersion of smaller particles in the solvent, which led to improved particle distribution on the PES membrane surface. Most importantly, the membrane modified by smaller particles displayed the best separation performance by rejecting $80.43 \%$ bovine serum albumin (BSA), and exhibited the highest antifouling properties by recovering $86.03 \%$ of its flux after tested with foulant-contained solution. As a comparison, the PES membrane with larger particles only showed $77.65 \%$ BSA rejection and $75.23 \%$ flux recovery rate.

Keywords: Hollow fiber, Membrane, Iron oxide, Wastewater, Antifouling performance.

\section{Introduction}

The rapid development of membrane technology for various water/wastewater treatment processes over the past decades can be ascribed to its high separation efficiency, cost effectiveness, low system footprint and low energy consumption [1, 2]. Ultrafiltration (UF) membranes have been commonly used in large scale treatment processes due to its efficiency in removing suspended and dissolved particles present in industrial wastewater [3]. However, membrane surface fouling remains as a key challenge both in the past and in the present. To address this issue, different kinds of surface modification methods have been proposed and studied by membrane scientists to tailor membrane surface characteristics and one popular strategy is to use inorganic particles to enhance membrane matrix, forming composite membrane with improved properties [4]. Such innovation that combines the intrinsic characteristics of polymer matrix and unique properties of particles has drawn attention for the past decade. Particles that 
have been used to develop composite membranes include graphene oxide $(\mathrm{GO})[5,6]$, titanium oxide (TiO2) $[7,8]$ and carbon nanotubes (CNTs) $[9,10]$.

Besides these particles, recent studies have reported on the viability of utilizing iron oxide $\left(\mathrm{Fe}_{3} \mathrm{O}_{4}\right)$ particles in modifying polymeric membrane matrix for enhanced permeability and rejection. $\mathrm{Fe}_{3} \mathrm{O}_{4}$ particles offer good characteristics such as good hydrophilicity, large surface area, easily available, low toxicity and chemically stable [11-13]. The abundance of hydroxyl functional groups on its surface makes it highly hydrophilic, which is the key feature in fabricating membrane with excellent filtration performance and fouling resistance. Most importantly, the commercial $\mathrm{Fe}_{3} \mathrm{O}_{4}$ ( USD 1.63 per gram) [14] is much cheaper compared to the carbon-based particles such as GO (up to USD 500 per gram) [15] and CNTs ( USD 40 per gram) [16]. This makes the commercial $\mathrm{Fe}_{3} \mathrm{O}_{4}$ much more competitive and practical to be used to modify membranes.

In a study conducted by Said et al. [17], it was reported that when $0.2 \mathrm{wt} \% \mathrm{Fe}_{3} \mathrm{O}_{4}$ nanoparticles was added into polysulfone (PSf)-based membrane, it improved both the pure water flux (from 40.47 to 57.04 $\mathrm{L} / \mathrm{m}^{2}$.h.bar) and bovine serum albumin (BSA) rejection (from 91.14 to $96.43 \%$ ) of the resultant membrane. Koulivand et al. [18], on the other hand, found that antifouling properties of polyethersulfone (PES) membrane was enhanced upon the incorporation of $0.5 \mathrm{wt} \%$ amine-modified $\mathrm{Fe}_{3} \mathrm{O}_{4}$ nanoparticles. The resultant membrane was reported to exhibit $\sim 40 \%$ reduction in water contact angle (corresponded to improved hydrophilicity), which contributed to $34.16 \%$ enhancement in flux recovery rate compared to neat PES membrane. The improvement between the $\mathrm{Fe}_{3} \mathrm{O}_{4}$-modified membrane surface and water molecules made the membrane more resistance toward hydrophobic foulants.

Although PES has been widely used as the base material for UF membrane synthesis [19, 20], the membranes made of this material still suffer from the fouling owing to its hydrophobic nature and low surface energy. This limitation reduces membrane fouling resistance which causes a decline in fluid transport properties during operation. Hence, incorporating hydrophilic $\mathrm{Fe}_{3} \mathrm{O}_{4}$ nanoparticles could offer a solution to tackle the hydrophobicity issue of PES membrane while providing other features such as improved water production rate [21, 22]. It has been previously reported that excessive incorporation of nanoparticles into the polymeric membrane matrix would adversely affect the structural integrity, leading to not only poor removal rate (due to enlarged pore size) but also reduced mechanical properties. This is due to the severe particle aggregation that can't be prevented during membrane fabrication process [23-25]. Thus, many studies recommended to introduce only small quantity of nanoparticles $(0.1-0.5$ wt $\%)$ to modify the membrane $[12,13,18,26]$.

Besides the quantity of particles used, another main factor that can result in the formation of different membrane properties is the use of different particle sizes. In general, particles of smaller size are favorable as it provides larger surface area for interfacial interactions between nanomaterial and membrane matrix [27-29]. For example, Mollahosseini et al. [30] reported the membrane modified by smaller silver particles (30 nm) exhibited better morphological structures (i.e., smoother surface and existence of more finger-like structure) in comparison to the membrane modified by larger silver particles $(70 \mathrm{~nm})$ and this subsequently showed better membrane permeability and antibacterial performance. However, it must be pointed out that incorporating particles with size $<100 \mathrm{~nm}$ into dope solution is challenging due to strong van der Waals interaction that induces agglomeration between the particles. This might compromise its positive features in the membrane [2].

Considering there is pros and cons of using particles of different sizes in modifying the membrane, this study aims to provide better insight on the influence of particles sizes of $\mathrm{Fe}_{3} \mathrm{O}_{4}$ (i.e., $50-100 \mathrm{~nm}$ and $<5$ $\mu \mathrm{m}$ ) on the properties of PES hollow fiber membranes for water treatment. To the best of our knowledge, the size effects of $\mathrm{Fe}_{3} \mathrm{O}_{4}$ on membrane properties have yet been reported in the literature. With respect to the price, the 5- $\mu \mathrm{m} \mathrm{Fe}_{3} \mathrm{O}_{4}$ costs approximately USD 1.08 per gram [31], i.e., 33.74\% cheaper than that of $\mathrm{Fe}_{3} \mathrm{O}_{4}$ of $50-100 \mathrm{~nm}$ ( USD 1.63 per gram). The membranes modified by two different $\mathrm{Fe}_{3} \mathrm{O}_{4}$ will be investigated in this work with respect to physical/chemical structure and dispersibility before being introduced into PES membrane matrix at fixed loading $(0.1 \mathrm{wt} \%)$. It is followed by membrane filtration performance assessment and antifouling study. 


\section{Materials and methods}

\section{Materials}

Commercial PES pellets (Ultrason®E) purchased from BASF SE, Germany were the main component in the formation of hollow fiber membrane. N-methyl-2-pyrrolidone (NMP, Purity >99\%) and polyvinylpyrrolidone (PVP) (molecular weight: 90,000 $\mathrm{g} / \mathrm{mol}$ ) supplied by Sigma Aldrich, USA were used as a solvent and pore former, respectively during dope solution preparation. $\mathrm{Fe}_{3} \mathrm{O}_{4}$ particles with two different sizes (50-100 nm and $<5 \mu \mathrm{m}$ ) were obtained from Sigma Aldrich, USA and used to improve the properties of hollow fiber membranes. Both particles are then labelled as $50-n m \mathrm{Fe}_{3} \mathrm{O}_{4}$ and $5-\mu m \mathrm{Fe}_{3} \mathrm{O}_{4}$, respectively. All the chemicals were used without further purification.

\section{Characterization of $\mathrm{Fe}_{3} \mathrm{O}_{4}$ Particles}

The morphology of $\mathrm{Fe}_{3} \mathrm{O}_{4}$ particles was observed using transmission electron microscope (TEM, JEOL, JEM-ARM 200F). X-ray diffractometry (XRD) was conducted by using X-ray diffractometer (Rigaku, SmartLab SE) to examine the phase composition of $\mathrm{Fe}_{3} \mathrm{O}_{4}$ particles. To detect all possible peaks, the measurement was performed in the angular of $2 \theta$ ranged $10^{\circ}$ to $90^{\circ}$. Fourier transform infrared (FTIR) spectroscopy was carried out using (Thermo Fisher Scientific, Nicolet 5700) to identify the functional groups present in $\mathrm{Fe}_{3} \mathrm{O}_{4}$ particles. The sample for FTIR analysis was prepared by mixing $100 \mathrm{mg}$ and 1 $\mathrm{mg}$ of potassium bromide $(\mathrm{KBr})$ and compressing it to form a pellet. Brunauer-Emmett-Teller surface analysis (BET, Quantachrome, NOVA 2200E) was conducted via adsorption/desorption measurement of nitrogen gas at $130^{\circ} \mathrm{C}$ to determine the specific surface area of $\mathrm{Fe}_{3} \mathrm{O}_{4}$ particles. The dispersibility of $\mathrm{Fe}_{3} \mathrm{O}_{4}$ particles in NMP solvent was examined based on the sedimentation speed of the particles in the solvent that was observed in the period of 30 days. $0.01 \mathrm{mg} / \mathrm{mL} \mathrm{Fe}_{3} \mathrm{O}_{4}$ suspension was prepared followed by sonication for $30 \mathrm{~min}$. The settling condition of the respective particles was then monitored by recording the turbidity of suspension at different time intervals using a turbidimeter $(\mathrm{HACH}, 2100 \mathrm{Q})$.

\section{Preparation of Hollow Fiber Membranes}

Three different dope solutions were prepared in this work and the dope formulation was similar to the study of Vatanpour et al. [32], except different type of nanoparticles was used. A control membrane sample was prepared using the dope solution composed of $20 \mathrm{wt} \%$ PES, $79 \mathrm{wt} \%$ NMP and $1 \mathrm{wt} \%$ PVP. The dope solution was prepared by adding PVP in NMP solvent. It was then subject to 5-h continuous stirring at $300 \mathrm{rpm}$ until a homogenous solution was obtained. Dried PES pellets were then added into the dope solution gradually (to avoid agglomeration) and mechanically stirred for $24 \mathrm{~h}$ at $500 \mathrm{rpm}$ until completely dissolved. The process of preparing $\mathrm{Fe}_{3} \mathrm{O}_{4}$-contained dope solutions was very similar to the control dope solution, except that $0.1 \mathrm{wt} \% \mathrm{Fe}_{3} \mathrm{O}_{4}$ particles were added into prepared PVP/NMP mixture (by reducing the weight of NMP by $0.1 \mathrm{wt} \%$ ) followed by $30-\mathrm{min}$ sonication at $50^{\circ} \mathrm{C}$ prior to polymer pellets addition.

Prior to membrane fabrication, each dope solution was degassed to remove any trapped air bubbles. The dope solution viscosity was determined using a viscometer (Cole Palmer, EW-98965-40) at $25^{\circ} \mathrm{C}$. Hollow fiber membranes were then fabricated using the prepared dope solutions at room conditions via dry/wet spinning technique. The spinning parameters were kept constant throughout the spinning process. The dope solution was extruded through an annular 630 stainless-steel spinneret with an orifice diameter/inner diameter of $1.2 \mathrm{~mm} / 0.8 \mathrm{~mm}$ at a speed of $6 \mathrm{~mL} / \mathrm{min}$, assisted by a gear pump to control the dope extrusion rate. The bore fluid was delivered through the inner diameter of spinneret at 2.0 $\mathrm{mL} / \mathrm{min}$ with the aid of a syringe pump. Then, the as-spun fibers were passed through 10-cm air gap before being guided through coagulation bath at rate of $4 \mathrm{~m} / \mathrm{min}$. Tap water was used as the external coagulant while pure water was utilized as the internal coagulant. The nascent hollow fiber membranes were cut then immersed in a water bath for $24 \mathrm{~h}$ to completely remove residual solvent. Lastly, the membranes were then treated with $10 \%$ glycerol solution overnight followed by air-drying.

\section{Characterization of Hollow Fiber Membranes}

The morphologies of fabricated hollow fiber membranes were examined using a field emission scanning 
electron microscope (FESEM, Hitachi, SU8020). The membrane sample was fractured in a liquid nitrogen and sputter-coated with platinum prior to imaging. Energy dispersive X-ray (EDX) spectroscope was also used along the FESEM analysis to detect iron (Fe) element and its distribution on the $\mathrm{Fe}_{3} \mathrm{O}_{4}$ modified membrane surface.

The hydrophilicity degree of hollow fiber membranes was determined using contact angle goniometer (Dataphysics, OCA 15Pro) based on a sessile drop method. A droplet of water $(0.5 \mu \mathrm{L})$ was produced by a microsyringe and placed onto the outer surface of a fiber. The water contact angle was then estimated by SCA20 software. The average of 15 measurements at different points of the sample surface was then calculated and reported.

The bulk porosity of membrane was determined by soaking the fibers in deionized water for $24 \mathrm{~h}$. After removing the excessive water from the sample, the wet membrane weight was recorded. The sample was subsequently dried for $24 \mathrm{~h}$ at $80^{\circ} \mathrm{C}$ and weighed again. The bulk porosity $(\varepsilon, \%)$ was calculated using Equation 1:

$$
\varepsilon=\frac{\omega_{1}-\omega_{2}}{l \times A \times d_{w}} \times 100
$$

where $\omega_{1}$ and $\omega_{2}$ are the weight of wet and dry membrane samples, respectively. $A$ is the effective area of membrane $\left(\mathrm{m}^{2}\right), d_{w}$ is water density $\left(\mathrm{g} / \mathrm{cm}^{3}\right)$ and $l$ is membrane thickness $(\mathrm{m})$. The mean pore radius $\left(r_{m}\right)$ of the membrane is determined by the Guerout-Elford-Ferry equation as expressed in Equation 2 :

$$
r_{m}=\sqrt{\frac{(2.9-1.75 \varepsilon) \times 8 \mu l Q}{\varepsilon \times A \times \Delta P}}
$$

where $\mu$ represents viscosity of water (mPa.s), $\Delta P$ is the transmembrane pressure $(\mathrm{Pa})$ and $Q$ is permeate volume water per time $\left(\mathrm{m}^{3} / \mathrm{s}\right)$.

The thermal stability of hollow fiber membranes was carried out by using thermogravimetric analyzer (TA Instruments, TGA-Q500). $5 \mathrm{mg}$ of membrane sample was subjected to heating at a constant rate of $10^{\circ} \mathrm{C} / \mathrm{min}$ until the temperature hits $800^{\circ} \mathrm{C}$ under nitrogen gas atmosphere to obtain the thermal degradation profile of membranes. Using a universal testing machine (Instron, Instron 5567), the mechanical properties of prepared membranes were characterized by pulling the tensile load at a constant rate until it fractured. The sample gauge length and gauge speed were fixed at $50 \mathrm{~mm}$ and 10 $\mathrm{mm} / \mathrm{min}$, respectively. Five measurements were performed to yield the average value of each sample.

The pure water flux and BSA rejection of fabricated membranes were determined by using a lab-scale crossflow filtration system. The pure water permeation flux (PWF) of the membranes were acquired with pure water as feed. Each membrane module contained 5 units of hollow fibers with a length of approximately $10 \mathrm{~cm}$. Prior to any measurement, each membrane was compacted at 2 bar until a steady flux was achieved. After that, the pressure was lowered to 1 bar and measurement was started to record. The initial pure water flux $\left(J w_{1}\right)$ was determined using Equation 3:

$$
J w_{1}=\frac{Q}{A \times t}
$$

where $Q$ is the volume of permeated water $(\mathrm{L}), A$ is the effective membrane area $\left(\mathrm{m}^{2}\right)$ and $t$ is the permeation time $(\mathrm{h})$.

The protein separation of membrane was studied using $1.0 \mathrm{~g} / \mathrm{L}$ of BSA solution in which the protein fluxes were recorded at 1 bar until the flux reached a constant value $\left(J_{p}\right)$. The recorded flux decline $\left(R_{F D}\right)$ during protein filtration was determined using Equation 4:

$$
R_{F D}=\left(1-\frac{J_{P}}{J_{W 1}}\right) \times 100
$$


UV-vis spectrophotometer ( $\mathrm{HACH}$, DR5000) was used to study the quality of the collected permeate. The protein rejection $(\mathrm{R})$ can be calculated using Equation 5:

$$
R=\left(1-\frac{C_{P}}{C_{f}}\right) \times 100
$$

where $C_{p}$ is the permeate concentration $(\mathrm{mg} / \mathrm{L})$ and $C_{f}$ is the protein feed concentration $(\mathrm{mg} / \mathrm{L})$, After the protein rejection analysis, the membrane was cleaned with distilled water for $15 \mathrm{~min}$. The pure water flux $\left(J_{w 2}\right)$ of the clean membrane was calculated. To determine the antifouling performance of the hollow fiber membranes, the flux recovery rate (FRR), reversible $\left(R_{r}\right)$ and irreversible $\left(R_{i r}\right)$ fouling were determined using the equations as follows:

$$
\begin{aligned}
& F R R=\frac{J_{W 2}}{J_{W 1}} \times 100 \\
& R_{r}=\frac{J_{W 2}-J_{P}}{J_{W 1}} \times 100 \\
& R_{i r}=\frac{J_{W 1}-J_{W 2}}{J_{W 1}} \times 100
\end{aligned}
$$

\section{Results and discussion}

\section{Characteristics of $\mathrm{Fe}_{3} \mathrm{O}_{4}$ Particles}

Figure 1 shows the TEM images of $\mathrm{Fe}_{3} \mathrm{O}_{4}$ particles of two different sizes, i.e., $5 \mu \mathrm{m}$ and $50 \mathrm{~nm}$. The micrographs show that 5- $\mu \mathrm{m} \mathrm{Fe}_{3} \mathrm{O}_{4}$ exhibited hexagonal shape with particle size ranges from 100 to 130 $\mathrm{nm}$, while $50-\mathrm{nm} \mathrm{Fe}_{3} \mathrm{O}_{4}$ displayed the typical spherical structure with average size of $\leq 24 \mathrm{~nm}$. Our results showed that the particle size as specified by the producer for the $5-\mu m \mathrm{Fe}_{3} \mathrm{O}_{4}$ is in fact much smaller under the TEM observation, but these particles are still larger compared to the $50-\mathrm{nm} \mathrm{Fe}_{3} \mathrm{O}_{4}$ sold by the same producer. The TEM images also revealed that the $50-\mathrm{nm} \mathrm{Fe}_{3} \mathrm{O}_{4}$ nanoparticle appeared to be more distinctive and well-defined compared to the $5-\mu \mathrm{m} \mathrm{Fe}_{3} \mathrm{O}_{4}$. The large clump demonstrated by $5-\mu \mathrm{m} \mathrm{Fe}_{3} \mathrm{O}_{4}$ is mainly due to the overlapping among particles and this makes distinct particles rather difficult to spot. The BET analysis revealed that the specific surface area of $5-\mu \mathrm{m}$ and $50-\mathrm{nm} \mathrm{Fe}_{3} \mathrm{O}_{4}$ is significantly different. The $50-\mathrm{nm} \mathrm{Fe}_{3} \mathrm{O}_{4}$ showed $39.99 \mathrm{~m}^{2} / \mathrm{g}$, which is about 6 times higher compared to the $5-\mu \mathrm{m}$ $\mathrm{Fe}_{3} \mathrm{O}_{4}$ of $7.12 \mathrm{~m}^{2} / \mathrm{g}$. The surface area of $50-\mathrm{nm} \mathrm{Fe} \mathrm{O}_{4}$ is within the range of $20-50 \mathrm{~m}^{2} / \mathrm{g}$ specified by the manufacturer. Its small crystallite size renders higher exposed surface area, leading to higher particle surface area than that of $5-\mu \mathrm{m} \mathrm{Fe}_{3} \mathrm{O}_{4}$.

The phase composition of $\mathrm{Fe}_{3} \mathrm{O}_{4}$ particles was analyzed using XRD analysis and the results are shown in Figure 2a. The peaks were identified based on the Joint Committee on Powder Diffraction Standards (JCPDS) database as reported previously [33-35]. The XRD spectra revealed that the cubic spinel phase of both $\mathrm{Fe}_{3} \mathrm{O}_{4}$ particles were consistent with the JCPDS 01-1111. The diffraction peaks at $2 \theta$ of $18.28^{\circ}$, $30.09^{\circ}, 35.46^{\circ}, 37.07^{\circ}, 43.09^{\circ}, 53.40^{\circ}, 56.99^{\circ}, 62.60^{\circ}$ and $73.91^{\circ}$ were respectively assigned to lattice planer orientations of (111), (220), (311), (222), (400), (422), (511), (440) and (533). The higher peak intensity displayed by $50-\mathrm{nm} \mathrm{Fe}_{3} \mathrm{O}_{4}$ is due to its stronger crystalline structure compared to the $5-\mu \mathrm{m}$ $\mathrm{Fe}_{3} \mathrm{O}_{4}$. This is because the peak intensity is determined by the interference of the individual atoms on the nanoparticle crystal planes [36, 37]. However, different size of $\mathrm{Fe}_{3} \mathrm{O}_{4}$ does not change the crystallinity of particles.

In Figure 2b, the FTIR spectra shows a strong peak at $590 \mathrm{~cm}^{-1}$ that is associated to the Fe-O functional group, while the broad peak between 3100 and $3600 \mathrm{~cm}^{-1}$ is corresponded to the stretching of $\mathrm{O}-\mathrm{H}$ group. These peaks indicated the presence of the functional groups in both $\mathrm{Fe}_{3} \mathrm{O}_{4}$ particles $[17,38]$. The broader $\mathrm{O}-\mathrm{H}$ peak possessed by $50-\mathrm{nm} \mathrm{Fe}_{3} \mathrm{O}_{4}$ compared to $5-\mu \mathrm{m} \mathrm{Fe}_{3} \mathrm{O}_{4}$ indicated that smaller particle has higher amount of hydroxyl groups than the bigger particle, making it more hydrophilic. Additionally, 
the peak found at $1621 \mathrm{~cm}^{-1}$ for $50-\mathrm{nm} \mathrm{Fe}_{3} \mathrm{O}_{4}$ can be associated to surface-adsorbed water on particle surface, which further increase its degree of hydrophilicity [39, 40].

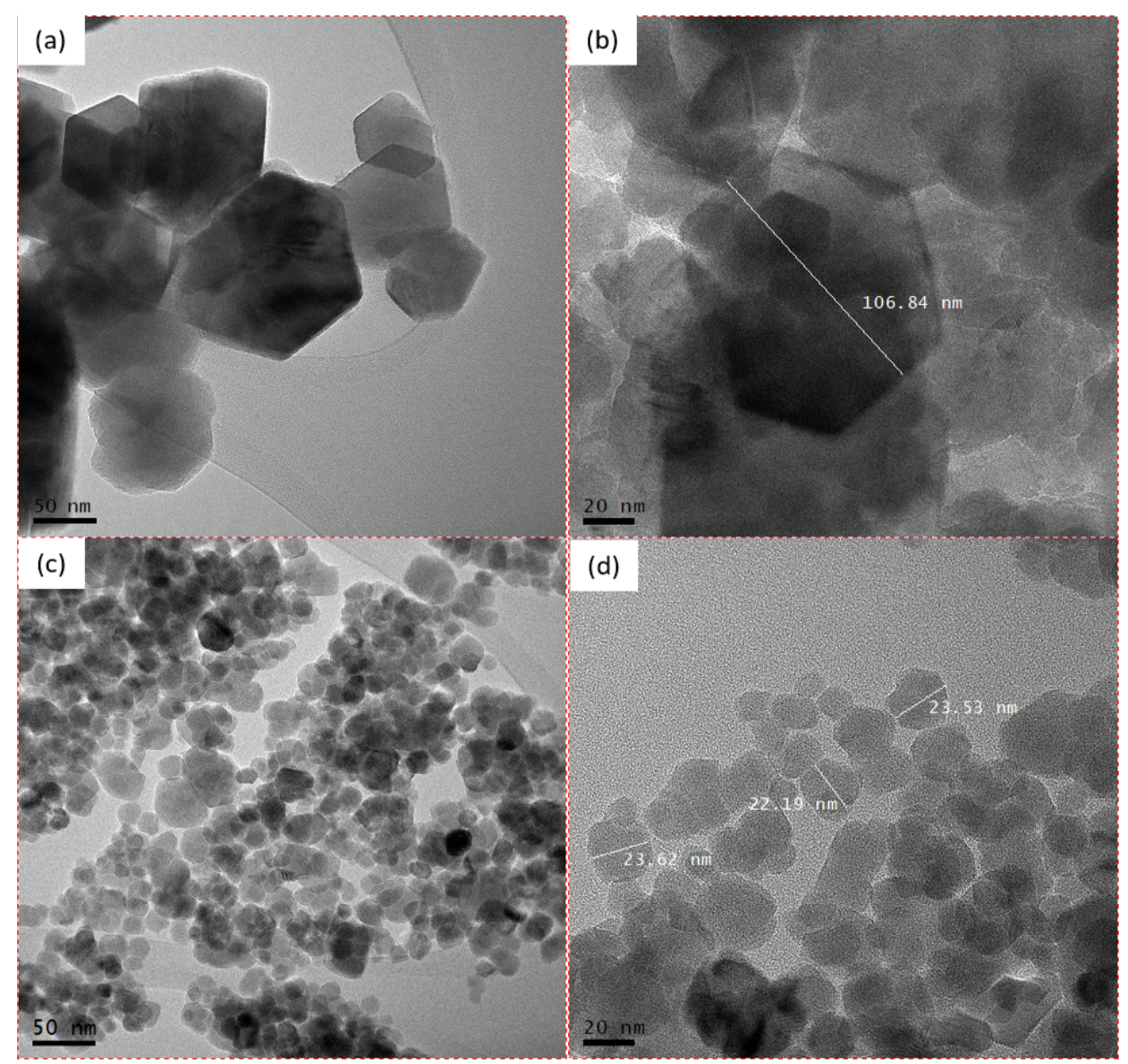

Figure 1.TEM micrographs of (a,b) $5-\mu m \mathrm{Fe}_{3} \mathrm{O}_{4}$ and (c,d) $50-\mathrm{nm} \mathrm{Fe}_{3} \mathrm{O}_{4}$ at scale bar of $200 \mathrm{~nm}$ and 20 $\mathrm{nm}$

(a)

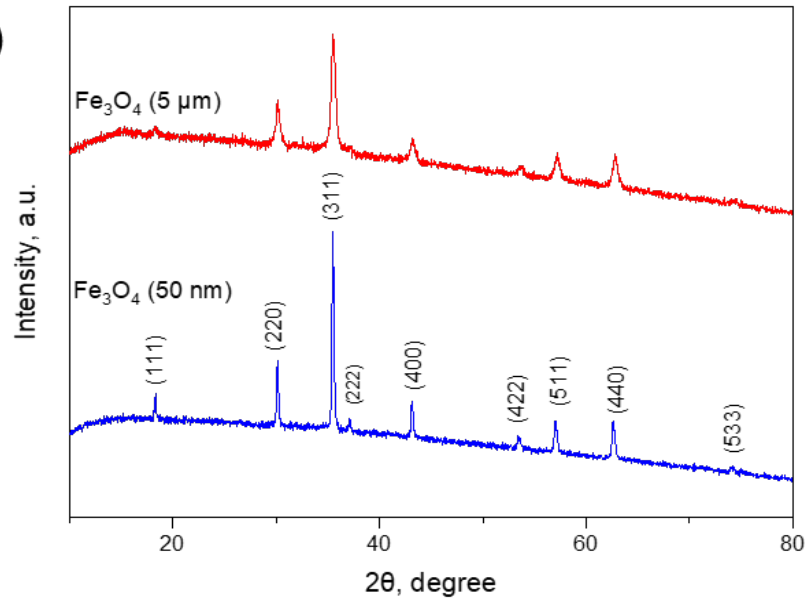

(b)

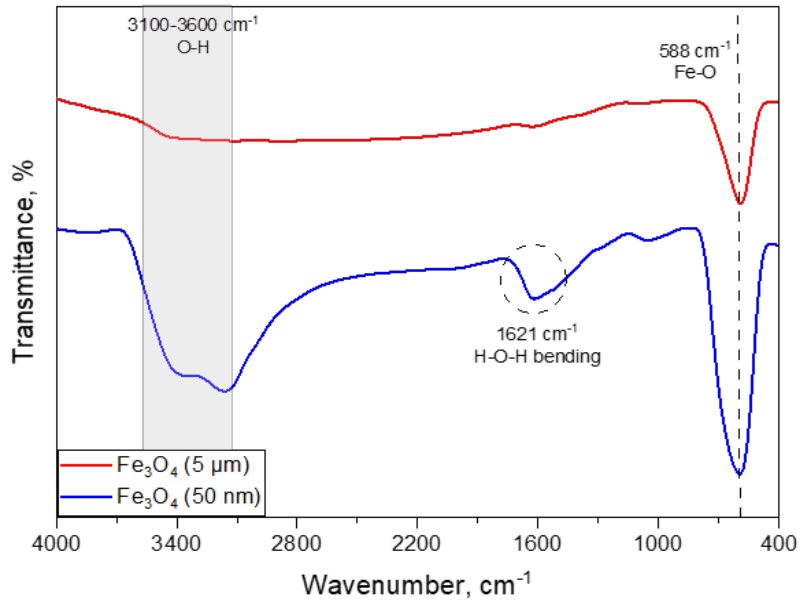

Figure 2. Characteristics of $\mathrm{Fe}_{3} \mathrm{O}_{4}$ particles, (a) XRD spectra and (b) FTIR spectra 
To further understand the distribution of $\mathrm{Fe}_{3} \mathrm{O}_{4}$ particles during membrane fabrication process, the dispersion behavior of both $\mathrm{Fe}_{3} \mathrm{O}_{4}$ particles sizes in organic solvent was observed for 30 days. As shown in Figure 3a, the 50-nm $\mathrm{Fe}_{3} \mathrm{O}_{4}$ exhibited greater stability in solvent compared to the larger $\mathrm{Fe}_{3} \mathrm{O}_{4}(5 \mu \mathrm{m})$. The higher the turbidity value the better the dispersibility of particles in solvent. Particle with poor dispersion would settle and precipitate faster which results in an almost transparent liquid supernatant. The visual comparison in Figure 3bi and 3bii showed that bigger $\mathrm{Fe}_{3} \mathrm{O}_{4}$ particle were less homogenous in comparison to smaller $\mathrm{Fe}_{3} \mathrm{O}_{4}$ particles as it has much higher sedimentation rate in the solvent. This is due to its larger size and heavier agglomeration clumps that promotes rapid precipitation, leading to poor stability in solvent. Smaller $\mathrm{Fe}_{3} \mathrm{O}_{4}(50 \mathrm{~nm})$ achieved better compatibility owing to the abundant $-\mathrm{OH}$ groups on its surface that improves its suspension stability in solvent. This is in line which previous works carried out by Goh et al. [41] and Gois et al. [42] where hydrophilic particle would facilitate stronger interaction between the particle and organic solvent, subsequently enhances its capability to disperse in solvent. This characteristic is very beneficial in producing particle-modified membranes with better characteristics.

(a)

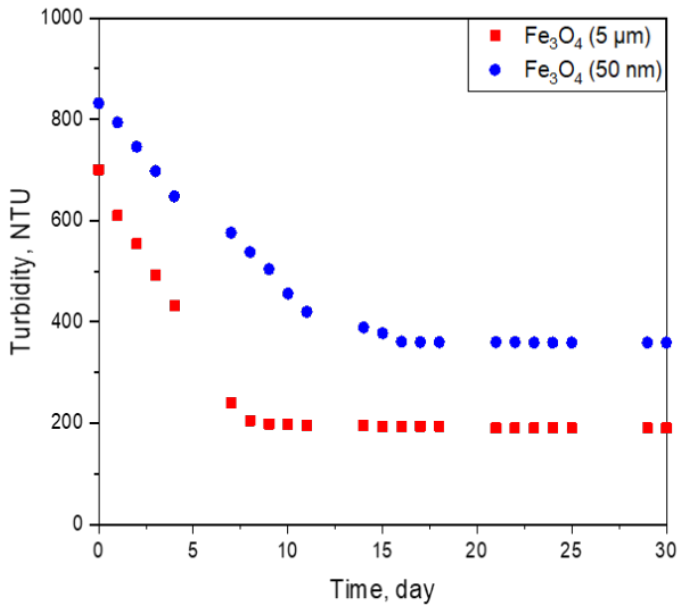

(b)i

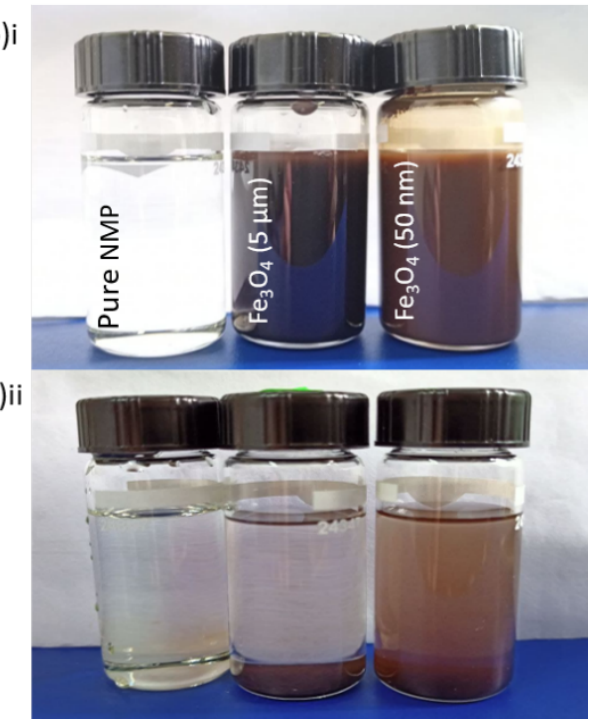

Figure 3. Dispersion stability performance of $5-\mu \mathrm{m}$ and $50-\mathrm{nm} \mathrm{Fe}_{3} \mathrm{O}_{4}$ in NMP solvent in terms of (a) turbidity profile and (b) visual comparison (i) before and (ii) after 30 days

\section{Membrane Morphology}

Based on the FESEM images shown in Figure 4, all hollow fiber membranes were observed to have the common asymmetric structure. The addition of PVP that acted as pore former, forming finger-like porous sublayer at the membrane outer layer. Neat PES membrane has larger macrovoids formed at the middle layer compared to the $\mathrm{Fe}_{3} \mathrm{O}_{4}$-modified PES membranes. The presence of $\mathrm{Fe}_{3} \mathrm{O}_{4}$ particles suppressed the formation of macrovoids, resulting in a more compact structure. The addition of particles was found to increase the viscosity of dope solution (see Table 1) which delayed the exchange rate of solvent and non-solvent in the phase inversion process. This produced the membranes with less macrovoids but more finger-like structures at the inner layer. Such mechanism also favored the formation of membrane with thinner walls, which is advantageous in increasing membrane water permeation due to reduced water transport resistance [3, 43].

The size of finger-like structures was more elongated with the incorporation of $50-\mathrm{nm} \mathrm{Fe}_{3} \mathrm{O}_{4}$ into PES membrane in comparison to the membrane with 5- $\mu \mathrm{F} \mathrm{Fe}_{3} \mathrm{O}_{4}$. PES membrane modified by smaller $\mathrm{Fe}_{3} \mathrm{O}_{4}$ also exhibited more porous structure with better interconnected pores in the sub-layer. This is due to higher hydrophilicity of smaller $\mathrm{Fe}_{3} \mathrm{O}_{4}(50 \mathrm{~nm})$ that could promote solvent/non-solvent exchange rate. The addition of $\mathrm{Fe}_{3} \mathrm{O}_{4}$ into polymeric matrix was found to develop the membranes with rougher surface and this is due to the deposition of fillers on membrane surface. Compared to the PES membrane 
incorporated with 5- $\mu \mathrm{m} \mathrm{Fe}_{3} \mathrm{O}_{4}$, the membrane with 50-nm $\mathrm{Fe}_{3} \mathrm{O}_{4}$ displayed smoother surface and better distribution of particles. As $5-\mu \mathrm{m} \mathrm{Fe}_{3} \mathrm{O}_{4}$ is bigger in size, it has higher tendency to form larger nodular shapes that result in the valleys development on the membrane surface. Smaller particle size has higher affinity with polymer matrix owing to its larger specific surface area that can interact better with polymeric chains, hence resulting in membrane with smoother surface $[8,28,30]$.

The successful integration of $\mathrm{Fe}_{3} \mathrm{O}_{4}$ particles in PES membranes was observed based on the EDX mapping of $\mathrm{Fe}$ element as shown in Figure 4. The PES/50-nm $\mathrm{Fe}_{3} \mathrm{O}_{4}$ membrane displayed uniform distribution throughout membrane surface compared to the PES/5- $\mu \mathrm{m} \mathrm{Fe}_{3} \mathrm{O}_{4}$ membrane. This can be attributed to the use of low nanoparticle loading $(0.1 \mathrm{wt} \%)$ that minimizes severe nanoparticle aggregates [29]. The higher hydrophilicity possessed by $50-\mathrm{nm} \mathrm{Fe}_{3} \mathrm{O}_{4}$ also greatly its interfacial adhesion and homogeneity with PES matrix, leading to an improvement in particle dispersion
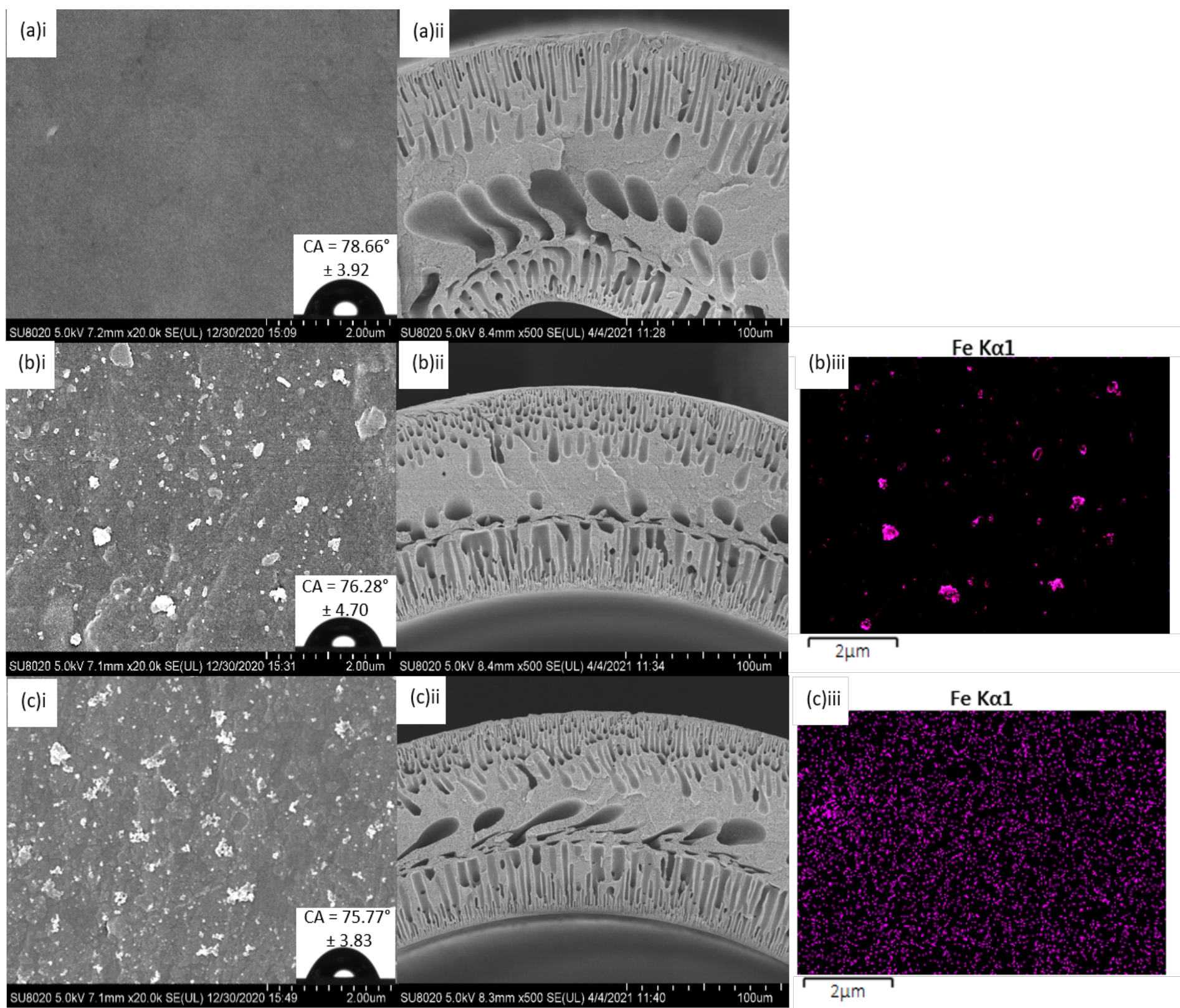

Figure 4. FESEM micrographs showing (i) membrane surface morphology (Inset: water contact angle), (ii) cross-section structure and (iii) EDX-Fe mapping for (a) PES, (b) PES/5- $\mu \mathrm{m} \mathrm{Fe}_{3} \mathrm{O}_{4}$ and (c) $\mathrm{PES} / 50-\mathrm{nm} \mathrm{Fe}_{3} \mathrm{O}_{4}$ membranes 


\section{Membrane Contact Angle, Porosity and Pore Size}

The water contact angle of membranes as shown in the inset in Figure 4 showed the following order, i.e., $\mathrm{PES}$ membrane $\left(78.66^{\circ}\right)>\mathrm{PES} / 5-\mu \mathrm{m} \mathrm{Fe} \mathrm{O}_{4}\left(76.28^{\circ}\right)>\mathrm{PES} / 50-\mathrm{nm} \mathrm{Fe} \mathrm{O}_{4}\left(75.77^{\circ}\right)$. As can be seen, the introduction of $\mathrm{Fe}_{3} \mathrm{O}_{4}$ particles could reduce the hydrophobic nature of PES membranes by decreasing water contact angle in which the membrane with smaller $\mathrm{Fe}_{3} \mathrm{O}_{4}$ displayed higher degree of hydrophilicity compared to larger $\mathrm{Fe}_{3} \mathrm{O}_{4}$. The lowest contact angle exhibited by the PES/50-nm $\mathrm{Fe}_{3} \mathrm{O}_{4}$ membrane is credited to its higher hydroxyl groups presented on its surface (see Figure $2 \mathrm{~b}$ ) and uniform dispersibility over membrane surface that boost membrane affinity towards water (see Figure 4ciii). Compared to the neat PES membrane, the contact angle of the $\mathrm{Fe}_{3} \mathrm{O}_{4}$-modified membranes is only slightly improved. This is due to increased surface roughness caused by particle addition that subsequently affects the water contact angle measurement due to the Wenzel/Cassie effect [44].

The porosity and pore size results as presented in Table 1 indicate that the incorporation of $\mathrm{Fe}_{3} \mathrm{O}_{4}$ positively influence the overall structural characteristics. The porosity of pristine PES membrane was increased from $39.46 \%$ to $44.69 \%$ and $50.33 \%$ upon the addition of $5-\mu m \mathrm{Fe}_{3} \mathrm{O}_{4}$ and $50-\mathrm{nm} \mathrm{Fe}_{3} \mathrm{O}_{4}$, respectively. The average pore size of $\mathrm{Fe}_{3} \mathrm{O}_{4}$-modified PES membranes is 2 times higher than the pristine PES membrane. As $50-\mathrm{nm} \mathrm{Fe}_{3} \mathrm{O}_{4}$ is much more hydrophilic than 5- $\mu \mathrm{m} \mathrm{Fe}_{3} \mathrm{O}_{4}$, the introduction of the smaller particle into dope solution results in faster demixing process. This developed the membrane with higher porosity and larger pore size as compared to the PES/5- $\mu \mathrm{m} \mathrm{Fe}_{3} \mathrm{O}_{4}$ and pristine PES membrane.

Table 1. Properties of hollow fiber membranes and dope solution.

\begin{tabular}{lcccr}
\hline Membrane & OD/ID [mm] & $\begin{array}{c}\text { Wall thickness } \\
{[\mathrm{mm}]}\end{array}$ & $\begin{array}{c}\text { Dope solution viscosity } \\
{[\mathrm{mPa} . \mathrm{s}]}\end{array}$ & $\begin{array}{c}\text { Porosity [\%] } \\
\text { Average pore size } \\
{[\mathrm{nm}]}\end{array}$ \\
\hline $\mathrm{PES}$ & $0.87 / 0.59$ & 0.141 & 5233 & $39.46 \pm 0.8$ \\
$\mathrm{PES} / 5-\mu \mathrm{m} \mathrm{Fe}_{3} \mathrm{O}_{4}$ & $0.89 / 0.65$ & 0.120 & 6859 & $26 \pm 1.2$ \\
$\mathrm{PES} / 50-\mathrm{nm} \mathrm{Fe} \mathrm{O}_{4}$ & $0.90 / 0.68$ & 0.106 & 7284 & $44.69 \pm 1.7$ \\
\hline
\end{tabular}

\section{Membrane Structural, Thermal and Mechanical Properties}

The FTIR spectra shown in Figure $5 a$ presented the effects of $\mathrm{Fe}_{3} \mathrm{O}_{4}$ incorporation into PES membranes. The absorption bands found at 1244,1488 , and $1580 \mathrm{~cm}^{-1}$ are associated with aromatic ether stretching, $\mathrm{C}-\mathrm{C}$ bond stretching and benzene ring stretching of PES organic structure, respectively. Meanwhile, the stretching bands observed at $3100-3700 \mathrm{~cm}^{-1}$ and $1656 \mathrm{~cm}^{-1}$ can be attributed to $\mathrm{O}-\mathrm{H}$ stretching and $\mathrm{H}-$ $\mathrm{O}-\mathrm{H}$ bending vibration, respectively. The successful incorporation of $\mathrm{Fe}_{3} \mathrm{O}_{4}$ particles into PES polymer matrix is indicated by the presence of the characteristic peak at $588 \mathrm{~cm}^{-1}$ as previously reported $[33,45]$. As the amount of $\mathrm{Fe}_{3} \mathrm{O}_{4}$ incorporated is relatively small $(0.1 \mathrm{wt} \%)$, it does not significantly alter the membrane's peaks. However, slightly higher peak intensities can be observed at $3200 \mathrm{~cm}^{-1}$ for the $\mathrm{Fe}_{3} \mathrm{O}_{4}$-modified membranes, indicating greater membrane hydrophilicity.

The impacts of $\mathrm{Fe}_{3} \mathrm{O}_{4}$ incorporation into PES membranes are further determined through thermal analysis as presented in Figure 5b. All PES membranes were observed to experience three regions of weight loss. The first weight loss occurred at $50-120^{\circ} \mathrm{C}$ was due to loss of residual adsorbed water and solvent in the membranes. The next region $\left(220-430^{\circ} \mathrm{C}\right)$ could be attributed to the degradation of polymer side chains. The third region at $580-1000^{\circ} \mathrm{C}$ was corresponded to the polymer backbone decomposition. The complete membrane degradation can be seen as the weight of the membranes remained constant beyond $850^{\circ} \mathrm{C}$. The thermal stability of PES membranes was significantly enhanced as the onset decomposition temperature of $\mathrm{Fe}_{3} \mathrm{O}_{4}$-modified membranes was found to be higher than that of pristine PES membrane. The improvement in terms of thermal behavior can be ascribed to better compatibility between polymer matrix and $\mathrm{Fe}_{3} \mathrm{O}_{4}$ particles as the polymer chain showed higher resistance towards thermal degradation [22, 46].

The changes in mechanical properties of PES membranes before and after modification using $\mathrm{Fe}_{3} \mathrm{O}_{4}$ particles were evaluated in terms of stress-strain curves as shown in Figure 5c. Wang et al. [47] and 
Zhang et al. [48] have previously observed the positive impacts of $\mathrm{Fe}_{3} \mathrm{O}_{4}$ particles incorporation on the mechanical strength of PES membrane. In this work, the pristine PES membrane recorded the lowest tensile strength $\left(1.98 \mathrm{MPa}\right.$ ), whereas the $\mathrm{PES} / 5-\mu \mathrm{m} \mathrm{Fe}_{3} \mathrm{O}_{4}$ and $\mathrm{PES} / 50-\mathrm{nm} \mathrm{Fe}_{3} \mathrm{O}_{4}$ membranes demonstrated 2.12 and $2.40 \mathrm{MPa}$, respectively. The improvement in membrane elasticity and rigidity can be attributed to the presence of $\mathrm{Fe}_{3} \mathrm{O}_{4}$ that acts as cross-linking point between PES polymer chains.

The addition of $\mathrm{Fe}_{3} \mathrm{O}_{4}$ particles also resulted in stronger interfacial shear stress between fillers and polymer matrix, which can be observed based on the enhancement in membrane flexibility with respect to Young's modulus and elongation percentage, as presented in Figure $5 \mathrm{~d}$. The pristine PES membrane demonstrated the lowest Young's modulus and percent elongation with $106.82 \mathrm{MPa}$ and $1.76 \%$, respectively, while the PES/5- $\mu \mathrm{m} \mathrm{Fe}_{3} \mathrm{O}_{4}$ membrane showed $110.42 \mathrm{MPa}$ and $1.92 \%$. The highest Young's modulus (118.81 MPa) and elongation break (2.02\%) was recorded when 50-nm $\mathrm{Fe}_{3} \mathrm{O}_{4}$ was incorporated within the PES membrane. Although the membrane mechanical strength does not influence membrane filtration performance directly (due to low operating pressure of UF process), it is an equally important membrane properties as it guarantees membrane long duration UF performance [22, 26].

(a)

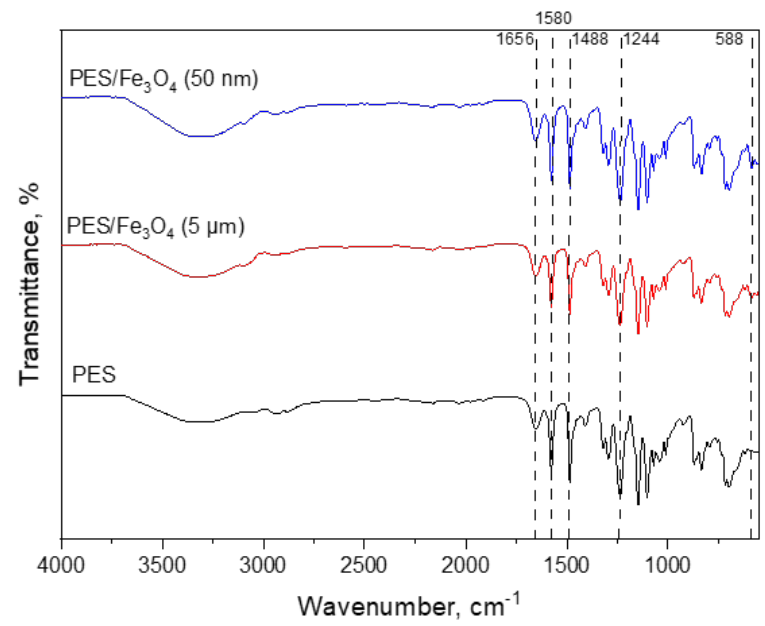

(c)

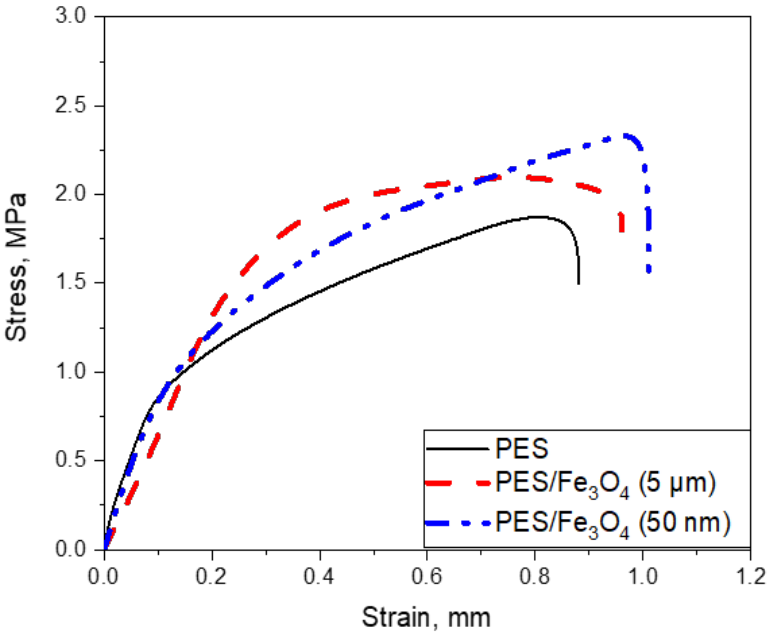

(b)

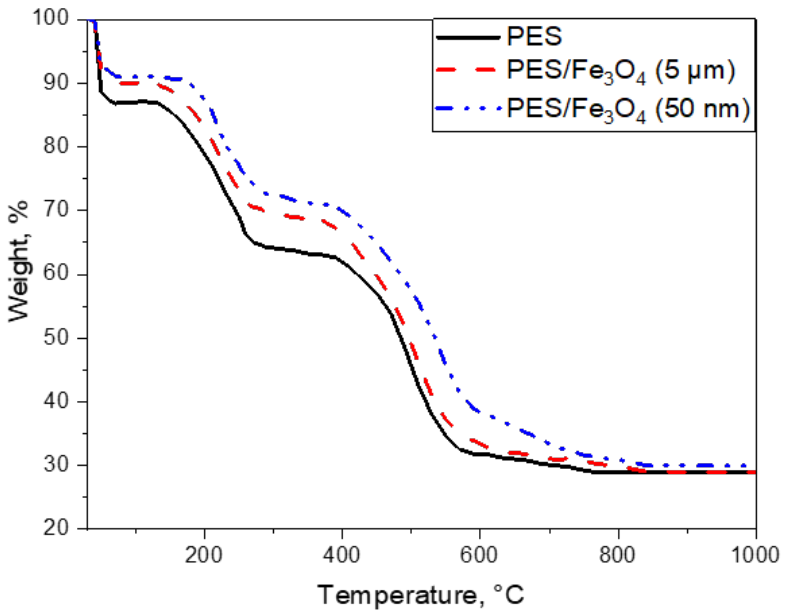

(d)

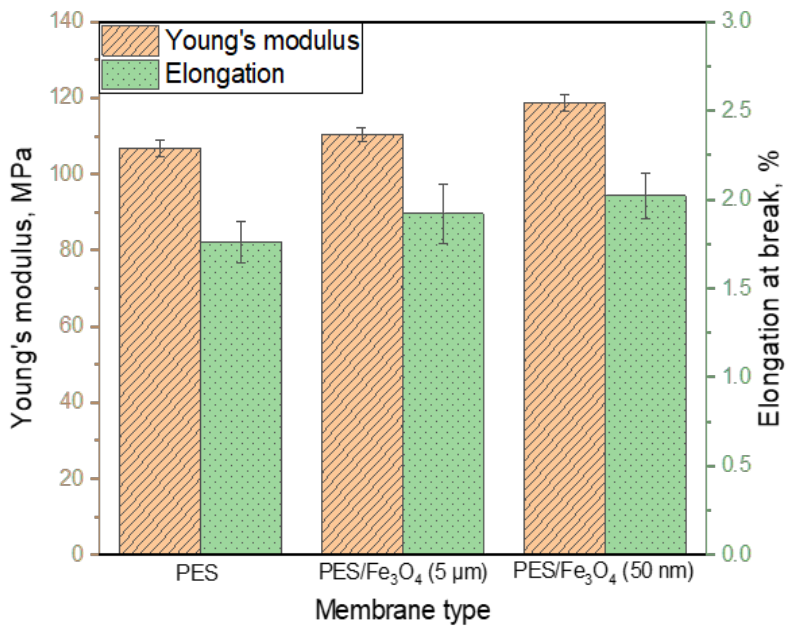

Figure 5. Properties of PES membranes in terms of (a) FTIR spectra, (b) TGA curves, (c) stress-strain curves and (d) Young's modulus and elongation at break 


\section{Membrane Filtration and Antifouling Performances}

Figure 6a presents the water flux and BSA rejection of different membranes. It can be observed that the PES/50-nm $\mathrm{Fe}_{3} \mathrm{O}_{4}$ membrane exhibited the highest PWF (110.42 L/m².h.bar) followed by PES/5- $\mu \mathrm{m}$ $\mathrm{Fe}_{3} \mathrm{O}_{4}\left(91.54 \mathrm{~L} / \mathrm{m}^{2}\right.$.h.bar) and pristine PES membrane $\left(82.60 \mathrm{~L} / \mathrm{m}^{2}\right.$.h.bar). The water flux profile indicates the importance of $\mathrm{Fe}_{3} \mathrm{O}_{4}$ and its size in improving membrane permeability. The incorporation of smaller $\mathrm{Fe}_{3} \mathrm{O}_{4}$ was better in enhancing the membrane water permeability mainly due to the improved membrane overall porosity and pore size. The morphological structure change and increased membrane hydrophilicity also greatly influenced water passage across the membrane. With respect to the BSA rejection, $\mathrm{PES} / 50-\mathrm{nm} \mathrm{Fe}_{3} \mathrm{O}_{4}$ membrane recorded $\mathrm{BSA}$ removal of $80.43 \%$ compared to $71.92 \%$ and $77.65 \%$ shown by the pristine PES and PES/5- $\mu \mathrm{m} \mathrm{Fe}_{3} \mathrm{O}_{4}$ membrane, respectively. The enhancement in surface hydrophilicity led to an increase in solute rejection, as membrane with higher wettability is able to prevent the adhesion of hydrophobic BSA molecules onto membrane surface.

Figure $6 \mathrm{~b}$ shows the antifouling performance of PES membranes determined by three-steps filtration process, with BSA as the protein foulant. The membranes recorded stable initial flux during the first 30 min of filtration with pure water as feed. The fluxes decreased rapidly when the feed solution was changed to BSA solution and this was mainly due to the concentration polarization and solute deposition on the membrane surface that created additional transport resistance. After cleaning with pure water, the membrane fluxes were able to be recovered to a certain extent, revealing that the flux decline is governed by reversible fouling.

As shown in Figure $6 \mathrm{c}$, despite being able to recover $73.49 \%$ of water flux after BSA solution filtration, the flux of pristine PES membrane was still lower compared to the $\mathrm{Fe}_{3} \mathrm{O}_{4}$-modified $\mathrm{PES}$ membranes that have higher degree of surface hydrophilicity. The PES/5- $\mu \mathrm{m} \mathrm{Fe}_{3} \mathrm{O}_{4}$ and PES/50-nm $\mathrm{Fe}_{3} \mathrm{O}_{4}$ membranes recorded FRR of $75.23 \%$ and $86.03 \%$, respectively. These findings indicated that the incorporation of hydrophilic particles into PES membrane matrix improved not only the membrane flux, but also its antifouling properties against BSA. The highest FRR achieved by PES/50-nm $\mathrm{Fe}_{3} \mathrm{O}_{4}$ membrane was mainly due to its lowest water contact angle and much better distribution of particles. These acted as a barrier against protein deposition onto PES membrane surface [29, 30]. Despite the high surface roughness of the modified PES membranes, the improved surface hydrophilicity outweighed the negative issue of rough surface in improving membrane antifouling ability [49].

The fouling potential of the membranes was further analyzed and their reversible fouling $\left(R_{r}\right)$, irreversible fouling $\left(R_{i r}\right)$ and total fouling rate $(R)$ are presented in Figure $6 \mathrm{~d}$. The low value of $R_{r}(11.76 \%), R_{\text {ir }}$ (13.97\%), and $\mathrm{R}(25.74 \%)$ exhibited by the PES/50-nm $\mathrm{Fe}_{3} \mathrm{O}_{4}$ membrane further confirmed its better antifouling performance than those of $\mathrm{PES} / 5-\mu \mathrm{m} \mathrm{Fe}_{3} \mathrm{O}_{4}$ membrane (13.76\%, 24.77\% and 38.53\%, respectively) and the pristine PES membrane $(31.93 \%, 26.51 \%$ and $58.43 \%$, respectively). The reduction in fouling tendencies in the $\mathrm{PES} / 50-\mathrm{nm} \mathrm{Fe}_{3} \mathrm{O}_{4}$ membrane can be associated to its lowest water contact angle, greatest hydrophilicity as well as uniformed particles distribution within polymer matrix, resulting in membrane with enhanced permeability and fouling resistant without the expense of its rejection performance. 
(a)

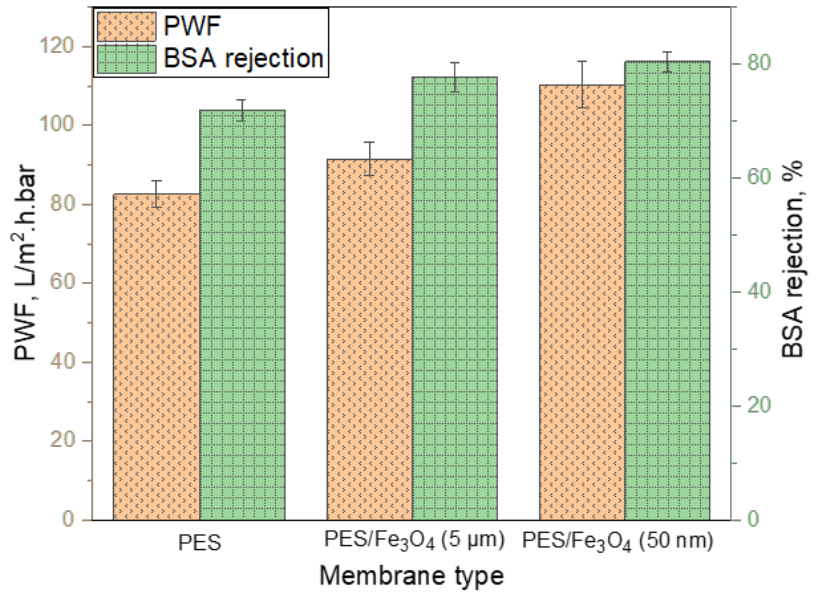

(c)

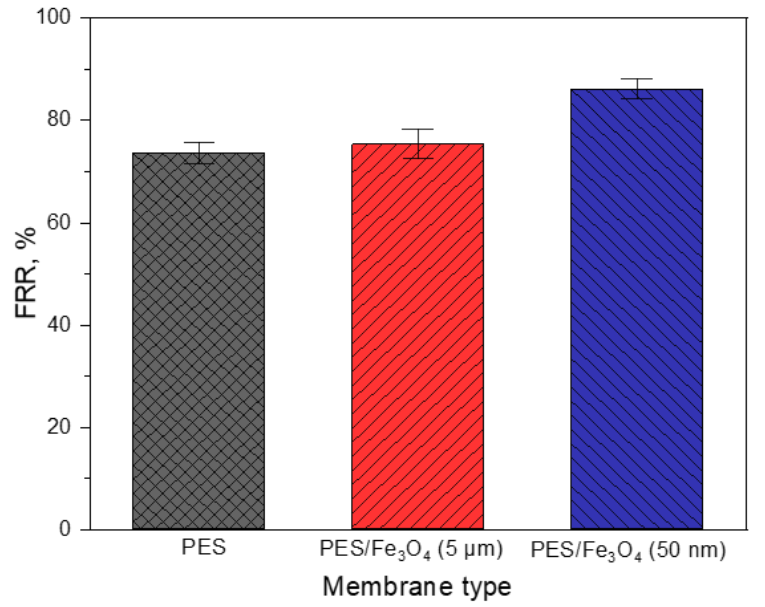

(b)

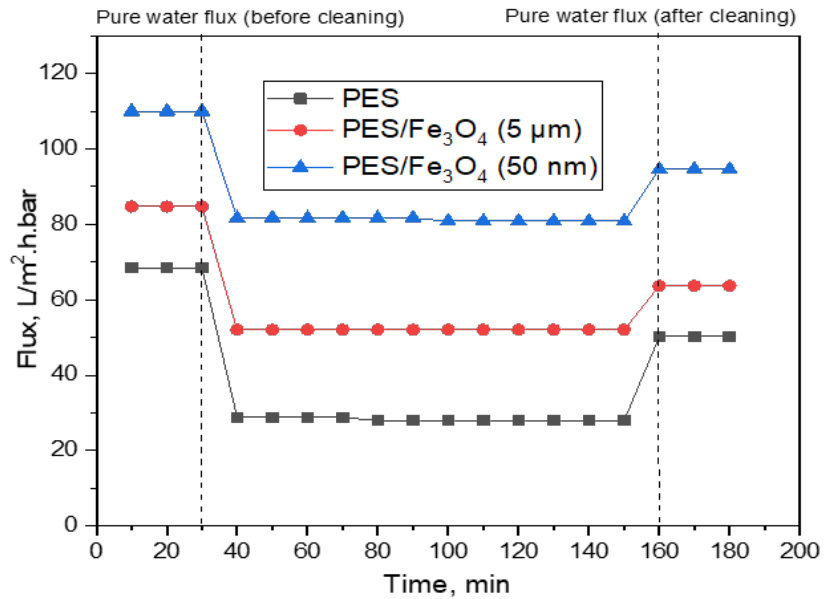

(d)

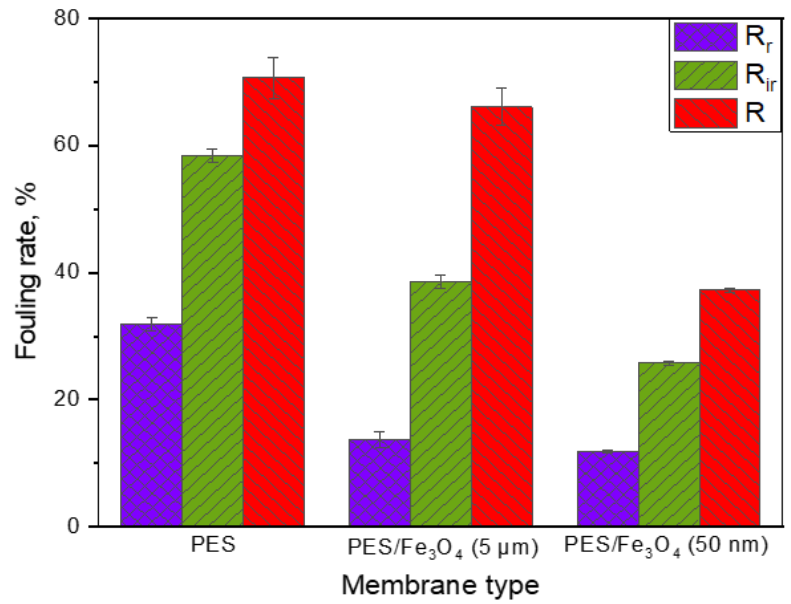

Figure 6. Membrane performance in terms of (a) PWF and BSA rejection and (b) Flux versus time during three steps filtration, (c) flux recovery rate (FRR) and (d) reversible, irreversible and total fouling rate

\section{Conclusion}

In this work, we performed a study to access if the $\mathrm{Fe}_{3} \mathrm{O}_{4}$ of different particle sizes did play a role in influencing the surface chemistry and morphology of PES hollow fiber membranes and thus their separation performance and antifouling properties. The results revealed that the smaller $\mathrm{Fe}_{3} \mathrm{O}_{4}(50 \mathrm{~nm})$ exhibited higher hydrophilicity and larger specific surface area compared to the larger $\mathrm{Fe}_{3} \mathrm{O}_{4}(5 \mu \mathrm{m})$ and these features are important in developing composite membrane for water treatment. In addition, the 50$\mathrm{nm} \mathrm{Fe}_{3} \mathrm{O}_{4}$ was found to disperse better in dope solution and could distribute evenly on the surface of membranes, forming a membrane with better structure integrity and improved mechanical and thermal properties. With respect to filtration performance, the PES/50-nm $\mathrm{Fe}_{3} \mathrm{O}_{4}$ membrane showed the best results in terms of pure water flux $\left(110.42 \mathrm{~L} / \mathrm{m}^{2}\right.$.h.bar) and BSA rejection $(80.43 \%)$. As a comparison, the $\mathrm{PES} / 5-\mu \mathrm{m} \mathrm{Fe} \mathrm{O}_{3} \mathrm{O}_{4}$ membrane only attained $91.54 \mathrm{~L} / \mathrm{m}^{2}$.h.bar and $77.65 \%$. The pristine PES membrane meanwhile showed the lowest performance $\left(82.60 \mathrm{~L} / \mathrm{m}^{2}\right.$.h.bar $\left.71.92 \%\right)$. This can be ascribed to positive role of $50-\mathrm{nm} \mathrm{Fe}_{3} \mathrm{O}_{4}$ in developing the membrane with the lowest contact angle, improved surface hydrophilicity and enhanced porosity. The improved surface chemistry of PES/50-nm $\mathrm{Fe}_{3} \mathrm{O}_{4}$ membrane also made it to have the highest FRR compared to the two other membranes, indicating improvement in antifouling properties. The findings of this study clearly demonstrated that the particle size of $\mathrm{Fe}_{3} \mathrm{O}_{4}$ does matter during nanocomposite membrane fabrication. Small $\mathrm{Fe}_{3} \mathrm{O}_{4}$ particles are found to have higher amount of hydroxyl groups than the big particles, making it more hydrophilic and beneficial to the membrane in terms of water flux and antifouling properties. More importantly, $\mathrm{Fe}_{3} \mathrm{O}_{4}$ particles are 
significantly cheaper compared to carbon-based nanoparticles and thus could offer practical solution in modifying polymeric membrane properties for water applications. In our next communication, we will report the impacts of different functionalization on the surface of $\mathrm{Fe}_{3} \mathrm{O}_{4}$ nanoparticles and how the surface modified $\mathrm{Fe}_{3} \mathrm{O}_{4}$ nanoparticles could further enhance membrane performance for water treatment.

\section{Data availability}

Data are available on request.

\section{Conflicts of interest}

The authors declare that there is no conflict of interest regarding the publication of this paper.

\section{Acknowledgment}

The first and corresponding authors would like to acknowledge Universiti Teknologi Malaysia (UTM) for providing financial support through the UTMSHINE Signature Research Grant (Vot no. Q.J130000.2451.07G79).

\section{References}

[1] P.S. Goh, A.F. Ismail, "A review on inorganic membranes for desalination and wastewater treatment," Desalination, 434, pp. 60-80, 2018. https://doi.org/10.1016/j.desal.2017.07.023

[2] L.Y. Ng, A.W. Mohammad, C.P. Leo, N. Hilal, "Polymeric membranes incorporated with metal/metal oxide nanoparticles: A comprehensive review," Desalination, 308, pp. 15-33, 2013. https://doi.org/10.1016/j.desal.2010.11.033

[3] N.A.M. Nazri, W.J. Lau, A.F. Ismail, "Improving water permeability and anti-fouling property of polyacrylonitrilebased hollow fiber ultrafiltration membranes by surface modification with polyacrylonitrile-g-poly(vinyl alcohol) graft copolymer," Korean J. Chem. Eng., 32, pp. 1853-1863, 2015. https://doi.org/10.1007/s11814-015-0017-y

[4] M.N. Subramaniam, P.S. Goh, Y.H. Tan et al., "Antifouling improvement of polyethersulfone membrane incorporated with negatively charged zinc-iron oxide for AT-POME colour removal," Arab. J. Sci. Eng., 44, pp. 5571-5580, 2019. http://dx.doi.org/10.1007/s13369-019-03858-y

[5] P.V. Chai, J.Y. Law, E. Mahmoudi, A.W. Mohammad, "Development of iron oxide decorated graphene oxide $\left(\mathrm{Fe}_{3} \mathrm{O}_{4} / \mathrm{GO}\right)$ PSf mixed-matrix membrane for enhanced antifouling behavior," J. Water Process. Eng., 38, pp. 101673, 2020. https://doi.org/10.1016/j.jwpe.2020.101673

[6] H. Ravishankar, J. Christy, V. Jegatheesan, "Graphene oxide (GO)-blended polysulfone (PSf) ultrafiltration membranes for lead ion rejection," Membranes, 8, pp. 77, 2018.

[7] C.S. Ong, W.J. Lau, P.S. Goh, B.C. Ng, A.F. Ismail, "Preparation and characterization of PVDF-PVP-TiO composite hollow fiber membranes for oily wastewater treatment using submerged membrane system," Desalin. Water Treat., 53, pp. 1213-1223, 2015. https://doi.org/10.1080/19443994.2013.855679

[8] H. Dzinun, Y. Ichikawa, H. Mitsuhiro, Q. Zhang, "Efficient immobilised $\mathrm{TiO}_{2}$ in polyvinylidene fluoride (PVDF) membrane for photocatalytic degradation of methylene blue," J. Membr. Sci. Res., 6, pp. 188-195, 2020. https://doi.org/10.22079/jmsr.2019.106656.1263

[9] M.S. Rameetse, O. Aberefa, M.O. Daramola, "Effect of loading and functionalization of carbon nanotube on the performance of blended polysulfone/polyethersulfone membrane during treatment of wastewater containing phenol and benzene," Membranes, 10, pp. 54, 2020.

[10] V. Vatanpour, A. Ghadimi, A. Karimi, A. Khataee, M.E. Yekavalangi, "Antifouling polyvinylidene fluoride ultrafiltration membrane fabricated from embedding polypyrrole coated multiwalled carbon nanotubes," Mater. Sci. Eng. C, 89, pp. 41-51, 2018. https://doi.org/10.1016/j.msec.2018.03.026

[11] S.M. Hosseini, M. Afshari, A.R. Fazlali et al., "Mixed matrix PES-based nanofiltration membrane decorated by ( $\mathrm{Fe}_{3} \mathrm{O}_{4}$-polyvinylpyrrolidone) composite nanoparticles with intensified antifouling and separation characteristics," Chem. Eng. Res. Des., 147, pp. 390-398, 2019. https://doi.org/10.1016/j.cherd.2019.05.025

[12] S. Zinadini, A.A. Zinatizadeh, M. Rahimi et al., "Novel high flux antifouling nanofiltration membranes for dye removal containing carboxymethyl chitosan coated $\mathrm{Fe}_{3} \mathrm{O}_{4}$ nanoparticles," Desalination, 349, pp. 145-154, 2014. https://doi.org/10.1016/j.desal.2014.07.007

[13] A. Gholami, A.R. Moghadassi, S.M. Hosseini, S. Shabani, F. Gholami, "Preparation and characterization of polyvinyl chloride based nanocomposite nanofiltration-membrane modified by iron oxide nanoparticles for lead removal from water," J. Ind. Eng. Chem., 20, pp. 1517-1522, 2014. https://doi.org/10.1016/j.jiec.2013.07.041 
[14] Iron (II,III) oxide nanopowder, 50-100 nm. (Sigma Aldrich, 2021), https://www.sigmaaldrich.com/US/ en/product/aldrich/637106?context=product. Accessed 3 July 2021

[15] Graphene oxide sheets. (Sigma Aldrich, 2021), https://www.sigmaaldrich.com/US/en/product/aldrich/ 763713 ? context=product. Accessed 3 July 2021

[16] Carbon nanotube, single-walled carbon $\geq 85 \%$, >70\% (carbon as SWNT), diam. 1.3-2.3 nm | 308068-56-6. (Sigma Aldrich, 2021), https://www.sigmaaldrich.com/US/en/product/aldrich/805033?context=product. Accessed 3 July 2021

[17] N. Said, H. Hasbullah, A.F. Ismail et al., "Enhanced hydrophilic polysulfone hollow fiber membranes with addition of iron oxide nanoparticles," Polym. Int., 66, pp. 1424-1429, 2017. https://doi.org/10.1002/pi.5401

[18] H. Koulivand, A. Shahbazi, V. Vatanpour, "Fabrication and characterization of a high-flux and antifouling polyethersulfone membrane for dye removal by embedding $\mathrm{Fe}_{3} \mathrm{O}_{4}-\mathrm{MDA}$ nanoparticles," Chem. Eng. Res. Des., 145, pp. 64-75, 2019. https://doi.org/10.1016/j.cherd.2019.03.003

[19] K. Rambabu, S. Velu, "Polyethylene glycol and iron oxide nanoparticles blended polyethersulfone ultrafiltration membrane for enhanced performance in dye removal studies," E-Polymers, 15, pp. 151-159, 2015. https://doi.org/10.1515/epoly-2014-0214

[20] M.S. Muhamad, M.R. Salim, W.J. Lau, "Preparation and characterization of $\mathrm{PES} / \mathrm{SiO}_{2}$ composite ultrafiltration membrane for advanced water treatment," Korean J. Chem. Eng., 32, pp. 2319-2329, 2015. https://doi.org/10.1007/s11814-015-0065-3

[21] D. Quemener, L. Upadhyaya, M. Semsarilar, A. Deratani, "Nanocomposite membranes with magnesium, titanium, iron and silver nanoparticles - a review," J. Membr. Sci. Res., 3, pp. 187-198, 2017 https://doi.org/10.22079/jmsr.2017.23779

[22] P.S. Goh, B.C. Ng, W.J. Lau, A.F. Ismail, "Inorganic nanomaterials in polymeric ultrafiltration membranes for water treatment," Sep. Purif. Rev., 44, pp. 216-249, 2015. https://doi.org/10.1080/15422119.2014.926274

[23] J. Kim, B. Van der Bruggen, "The use of nanoparticles in polymeric and ceramic membrane structures: Review of manufacturing procedures and performance improvement for water treatment," Environ. Pollut., 158, pp. 2335-2349, 2010. https://doi.org/10.1016/j.envpol.2010.03.024

[24] M. Zahid, A. Rashid, S. Akram, Z. Rehan, W. Razzaq, "A comprehensive review on polymeric nanocomposite membranes for water treatment," J. Membr. Sci. Tech., 08, pp., 2018. https://doi.org/10.4172/21559589.1000179

[25] Z. Xu, T. Wu, J. Shi et al., "Manipulating migration behavior of magnetic graphene oxide via magnetic field induced casting and phase separation toward high-performance hybrid ultrafiltration membranes," ACS Appl. Mater. Interfaces, 8, pp. 18418-18429, 2016. 10.1021/acsami.6b04083

[26] S. Ansari, E. Bagheripour, A. Moghadassi, S.M. Hosseini, "Fabrication of mixed matrix poly(phenylene etherether sulfone)-based nanofiltration membrane modified by $\mathrm{Fe}_{3} \mathrm{O}_{4}$ nanoparticles for water desalination," J. Polym. Eng., pp., 2016. https://doi.org/10.1515/polyeng-2015-0392

[27] Wang, T. Zheng, R. Xiong, P. Wang, J. Ma, "Strong improvement of reverse osmosis polyamide membrane performance by addition of ZIF-8 nanoparticles: Effect of particle size and dispersion in selective layer," Chemosphere, 233, pp. 524-531, 2019. https://doi.org/10.1016/j.chemosphere.2019.06.008

[28] H.J. Song, Y.J. Jo, S.-Y. Kim, J. Lee, C.K. Kim, "Characteristics of ultrafiltration membranes fabricated from polysulfone and polymer-grafted silica nanoparticles: Effects of the particle size and grafted polymer on the membrane performance," J. Membr. Sci., 466, pp. 173-182, 2014. https://doi.org/10.1016/j.memsci.2014.04.053

[29] V. Vatanpour, S.S. Madaeni, A.R. Khataee et al., " $\mathrm{TiO}_{2}$ embedded mixed matrix PES nanocomposite membranes: Influence of different sizes and types of nanoparticles on antifouling and performance," Desalination, 292, pp. 19-29, 2012. https://doi.org/10.1016/j.desal.2012.02.006

[30] A. Mollahosseini, A. Rahimpour, M. Jahamshahi, M. Peyravi, M. Khavarpour, "The effect of silver nanoparticle size on performance and antibacteriality of polysulfone ultrafiltration membrane," Desalination, 306, pp. 41-50, 2012. https://doi.org/10.1016/j.desal.2012.08.035

[31] Iron (II,III) oxide powder, $\quad<5 \quad \mu \mathrm{m} . \quad$ (Sigma Aldrich, 2021$)$ https://www.sigmaaldrich.com/US/en/product/aldrich/310069?context=product. Accessed 3 July 2021

[32] V. Vatanpour, H. Karimi, S. Imanian Ghazanlou et al., "Anti-fouling polyethersulfone nanofiltration membranes aided by amine-functionalized boron nitride nanosheets with improved separation performance," J. Environ. Chem. Eng., 8, pp. 104454, 2020. https://doi.org/10.1016/j.jece.2020.104454

[33] I.S. Al-Husaini, A.R.M. Yusoff, W.J. Lau et al., "Iron oxide nanoparticles incorporated polyethersulfone electrospun nanofibrous membranes for effective oil removal," Chem. Eng. Res. Des., 148, pp. 142-154, 2019. https://doi.org/10.1016/j.cherd.2019.06.006

[34] R.R. Darabi, M. Peyravi, M. Jahanshahi, A.A. Qhoreyshi Amiri, "Decreasing ICP of forward osmosis (TFN-FO) membrane through modifying PES- $\mathrm{Fe}_{3} \mathrm{O}_{4}$ nanocomposite substrate," Korean J. Chem. Eng., 34, pp. 2311-2324, 2017. https://doi.org/10.1007/s11814-017-0086-1

[35] V.A.J. Silva, P.L. Andrade, M.P.C. Silva et al., "Synthesis and characterization of $\mathrm{Fe}_{3} \mathrm{O}_{4}$ nanoparticles coated with fucan polysaccharides," J. Magn. Magn. Mater., 343, pp. 138-143, 2013. https://doi.org/10.1016/j.jmmm.2013.04.062 
[36] A.V. Vorontsov, S.V. Tsybulya, "Influence of nanoparticles size on XRD patterns for small monodisperse nanoparticles of $\mathrm{CuO}$ and $\mathrm{TiO}_{2}$ anatase," Ind. Eng. Chem. Res., 57, pp. 2526-2536, 2018. https://doi.org/10.1021/acs.iecr.7b04480

[37] C.F. Holder, R.E. Schaak, "Tutorial on powder X-ray diffraction for characterizing nanoscale materials," ACS Nano, 13, pp. 7359-7365, 2019. https://doi.org/10.1021/acsnano.9b05157

[38] B. Lesiak, N. Rangam, P. Jiricek et al., "Surface study of $\mathrm{Fe}_{3} \mathrm{O}_{4}$ nanoparticles functionalized With biocompatible adsorbed molecules," Front. Chem., 7, pp., 2019. https://doi.org/10.3389/fchem.2019.00642

[39] H. Veisi, S. Taheri, S. Hemmati, "Preparation of polydopamine sulfamic acid-functionalized magnetic $\mathrm{Fe}_{3} \mathrm{O}_{4}$ nanoparticles with a core/shell nanostructure as heterogeneous and recyclable nanocatalysts for the acetylation of alcohols, phenols, amines and thiols under solvent-free conditions," Green Chem., 18, pp. 6337-6348, 2016. https://doi.org/10.1039/C6GC01975G

[40] Y.S. Li, J.S. Church, A.L. Woodhead, "Infrared and Raman spectroscopic studies on iron oxide magnetic nanoparticles and their surface modifications," J. Magn. Magn. Mater., 324, pp. 1543-1550, 2012. https://doi.org/10.1016/j.jmmm.2011.11.065

[41] P.S. Goh, B.C. Ng, A.F. Ismail et al., "Effect of Dispersed Multi-Walled Carbon Nanotubes on Mixed Matrix Membrane for O2/N2 Separation," Sep. Sci. Tech., 46, pp. 1250-1261, 2011. http://dx.doi.org/10.1080/01496395.2011.554952

[42] G. Gois, N. Nepomuceno, C. França et al., "Influence of morphology and dispersion stability of CNC modified with ethylene oxide derivatives on mechanical properties of PLA-based nanocomposites," Polym. Compos., 40, pp., 2018. https://doi.org/10.1002/pc.24704

[43] A. Bildyukevich, T. Plisko, V. Usosky, "The formation of polysulfone hollow fiber membranes by the free fall spinning method," Petrol. Chem+, 56, pp. 379-400, 2016. https://doi.org/10.1134/S0965544116050042

[44] P. Jin, C. Huang, J. Li, Y. Shen, L. Wang, "Surface modification of poly(vinylidene fluoride) hollow fibre membranes for biogas purification in a gas-liquid membrane contactor system," Royal Society Open Science, 4, pp. 171321, 2017. https://doi.org/10.1098/rsos.171321

[45] E. Mosaffa, H. Ghafuri, H.R. Esmaili Zand, "Improvement on physical properties of polyethersulfone membranes modified by poly(1-vinylpyrrolidone) grafted magnetic $\mathrm{Fe}_{3} \mathrm{O}_{4} @ \mathrm{SiO}_{2}$ nanoparticles," Appl. Organomet. Chem., 33, pp. 4639, 2019. https://doi.org/10.1002/aoc.4639

[46] J. Liu, Y. Li, X. Wang, Q. Zhang, J. Yang, "Preparation and properties of nano-composite films based on polyethersulfone and surface-modified $\mathrm{SiO}_{2}, "$ J. Macromol. Sci. Part B, 50, pp. 2356-2365, 2011. https://doi.org/10.1080/00222348.2011.562825

[47] C. Wang, H. Wu, F. Qu et al., "Preparation and properties of polyvinyl chloride ultrafiltration membranes blended with functionalized multi-walled carbon nanotubes and MWCNTs/Fe $\mathrm{O}_{3} \mathrm{O}_{4}$ hybrids," J. Appl. Polym. Sci., 133, pp., 2016. https://doi.org/10.1002/app.43417

[48] Zhang, S. Chen, W. Hu et al., "Facile fabrication of flexible magnetic nanohybrid membrane with amphiphobic surface based on bacterial cellulose," Carbohyd. Polym., 86, pp. 1760-1767, 2011. https://doi.org/10.1016/j.carbpol.2011.07.015

[49] N. Ghaemi, S.S. Madaeni, P. Daraei et al., "Polyethersulfone membrane enhanced with iron oxide nanoparticles for copper removal from water: Application of new functionalized $\mathrm{Fe}_{3} \mathrm{O}_{4}$ nanoparticles," Chem. Eng. J., 263, pp. 101-112, 2015. https://doi.org/10.1016/j.cej.2014.10.103 